\title{
Update on the Fungal Biofilm Drug Resistance and Its Alternative Treatment
}

\author{
Karina Siow Yen Ng How Tseung, Jingjun Zhao* \\ Department of Dermatology and Venereology, Tongji Hospital, Tongji University School of Medicine, Shanghai, \\ China \\ Email: "zhaomyco@163.com
}

Received 31 March 2016; accepted 9 May 2016; published 12 May 2016

Copyright (C) 2016 by authors and Scientific Research Publishing Inc.

This work is licensed under the Creative Commons Attribution International License (CC BY). http://creativecommons.org/licenses/by/4.0/

(c) () Open Access

\begin{abstract}
Candida albicans (C. albicans) and Aspergillus fumigatus (A. fumigatus) are the two main pathogens in the clinical setting to cause serious, sometimes, lethal fungal infections. Immunocompromised patients fall victims to these fungi, with a mortality rate rising drastically over the past decades. This is in correlation with the fact that conventional antifungals are no longer capable of completely eradicating the disease, or if so, high doses are usually required to do so, leading to eventual resistance to those drugs and severe side effects. High drug resistance is in association with the discovery that these opportunistic pathogens have the ability to develop a multicellular complex, known as biofilm. Biofilms prevent drugs from reaching the fungal cells by sequestering them in their extracellular matrix. Other factors such as extracellular DNA, persister cells or heat shock protein 90 (Hsp90) also play a role in biofilm and contribute to drug recalcitrance. With the discovery of new antifungals lagging behind, scientists focused on other more profitable ways to counteract this phenomenon. Combination of two or more antifungals was found effective but came with serious drawbacks. Natural plant extracts, such as traditional Chinese medicine have also been demonstrated in vitro to possess antimicrobial actions. Great interest was directed towards their use with conventional antifungal agents with a possibility of lowering the necessary concentration required to inhibit the growth of fungi. This review aims in understanding the different factors contributing to clinical drug resistance and evaluating the effect of combination therapy and natural products on those cases difficult to treat.
\end{abstract}

\section{Keywords}

Aspergillus fumigatus, Candida albicans, Biofilm, Antifungal Resistance, Combination Therapy, Traditional Chinese Medicine

\footnotetext{
*Corresponding author.
} 


\section{Introduction}

In the last few decades, infection due to fungi has risen drastically with one of the most common causative agents being Candida spp., while Aspergillus spp. comes second. The most studied Candida spp., Candida albicans (C. albicans), is commonly found in a hospital setting where it adheres onto catheter material or human cell surfaces and adapts to a biofilm environment [1] [2]. The filamentous fungi, Aspergillus fumigatus (A. fumigatus) targets the lungs, leading to a variety of life threatening systemic diseases such as invasive aspergillosis. Research shows that immunocompromised patients, such as organ transplant recipients, people who are human immunodeficiency virus (HIV) positive, those suffering from leukemia or those under long-term therapy with glucocorticoids are the common targets of these pathogens [3] [4]. Mortality rate among these individuals has risen to $50 \%$ or higher over the past few years [5]. The mainstay antifungal therapy constitutes of polyene, azoles and echinocandins [6]. Although commonly used in the clinical setting, they unfortunately are not able to completely eradicate the invasive infections. Furthermore, with the lack in development of new antifungal agents, drug resistance in those patients still has a problem that is hard to resolve. This high rise in resistance comes in association with the fascinating discovery that pathogenic fungi are capable of producing a multicellular complex known as biofilm. This review aims to illustrate the different mechanisms involved in the drug recalcitrance of fungal biofilms. We also discuss the recent developments in the treatment of mycological infections.

\section{Biofilms and Their Resistance to Antifungal Agents}

Chronic A. fumigatus infection starts off by human beings inhaling the conidia from the surrounding air. A. fumigatus invasion is dependent on the ability of its conidia to germinate and evolve into mycelia. This mycelial structure eventually invades the pulmonary epithelial and endothelial cells. In terms of kinetics, the development of A. fumigatus biofilms is divided into initial adherence, conidial germination and maturation and differentiation [1] [7]. Histology and microscopic examination of bronchopulmonary lavage samples from aspergillosis patients have revealed that $A$. fumigatus forms multiple intertwined hyphae gathered into a complex multicellular mycetoma structure, similar to Candida species [8]. Although the life cycle of C. albicans and A. fumigatus are significantly different [9], they both have key aspects of cellular differentiation and the ability to form filamentous growth. Biofilms are by definition complex, highly organized communities of microorganisms; the fungal hyphae bind to each other forming a contiguous sheath onto a biotic or abiotic surface with the help of a hydrophobic extracellular matrix (ECM) [10] [11]. Antifungal resistance is a complex phenomenon that can be induced in response to a change in environment following prolonged exposure. Below is a list of characteristics fungal cells possess to combat the effects of antifungal treatment (Figure 1).

\subsection{Extracellular Matrix}

The presence of ECM satisfies the simple definition of a biofilm, it is composed of essentially cell wall-like po-

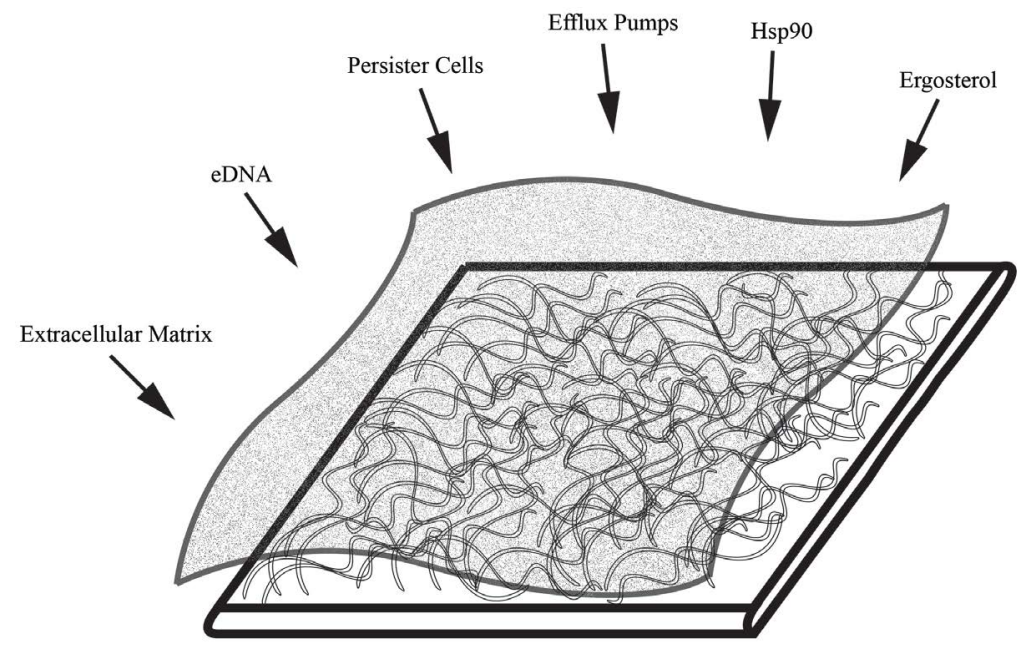

Figure 1. Characteristics of fungal biofilm in drug resistance. 
lysaccharides such as galactomannan, $a$-1,3-glucans, galactosaminogalactan, monosacharides, polyols, melanin, proteins [11]. They constitute approximately $43 \%$ of the ECM composition [12], ECM of microbial biofilms has also been shown to contain extracellular DNA (eDNA); Galactosaminogalactan, a polymer of galactose and $N$-acetylglucosamine plays a crucial role in the adherence and virulence of A. fumigatus. Galactomannan and $a-1,3$ glucans are two polysaccharides specific to A. fumigatus biofilms [11]. Catalase B and Asp $\mathrm{f} 2$ are the two main proteins identified in ECM of A. fumigatus biofilms [12]. Catalase B acts as a protective mechanism against reactive oxygen species, mostly hydrogen peroxide, during host infection; in addition, a rise in catalase production lowers the risk of microorganisms from being engulfed by phagocytes and eventually being killed [13]. Asp f2 on the other hand causes damage to the host epithelium and host inflammatory reactions during invasion of fungi [14]. Melanin is also an important component of fungal virulence in A. fumigatus biofilms as it targets the host's immune system during fungal infection [15]. ECM increases with time as biofilms continue to mature until the fungal communities is entirely engulfed within the matrix. Recent studies demonstrated that the ECM might play an important role in the enhancement of cell density, monitoring disaggregation and adaptation to nutritional requirements. Although the role of ECM in A. fumigatus biofilm is not completely understood, scientists believed it also functions as a physical barrier to antimicrobials due to its reduced permeability capable of delaying penetration of drugs upon reaching the cells [11]. However the intact composition of the matrix still remains to be meticulously explored as present technologies such as immunoassays only allow for quantitative descriptions of $A$. fumigatus biofilms that are restrained to soluble or low-molecular-weight components of the ECM [12].

\subsection{Extracellular DNA}

As mentioned in the previous section, eDNA is one of the key structural component of the ECM. Its presence in ECM of biofilm has been meticulously studied in bacterial biofilms, an example would be Pseudomonas aeruginosa in which studies showed that eDNA takes up to 2\% of the ECM contents [16]. eDNA from bacterial biofilms acts as a structural support as well as a nutrient source to the pathogen, it also facilitates the exchange of genetic information and contributes to the cell dispersal [17]. However, little is known concerning the presence of eDNA in fungal biofilms, studies limited to C. albicans showed that their biofilm's structural and architectural integrity were associated with an increase in eDNA as the biofilms matured [18]. It was demonstrated by Margarita Martins et al., when they investigated the presence of eDNA in C. albicans biofilm; C. albicans biofilm underwent a substantial inhibition of $40 \%$ upon addition of $0.13 \mathrm{mg} / \mathrm{ml}$ DNase. Studies suggested that it might be due to the DNase's direct effect on the ECM polymers, such as, $\alpha$-1,3-glucans, compromising its architectural structure and maintenance. They thus concluded that eDNA played an essential role in matured biofilms rather than young developing ones.

Rajendran et al. were the first to report the presence of eDNA in A. fumigatus. In their study, they were able to demonstrate that, similar to C. albicans, A. fumigatus biofilm matures with an increase in eDNA, a by-product of autolysis. eDNA might be a genomic DNA released from A.fumigatus during biofilm maturation. They also showed that the addition of DNase remarkably improved the antifungal effects of amphotericin B (8 fold reduction in minimum inhibitory concentration, MIC) or caspofungin ( 8 fold reduction in MIC) against 48 hours grown biofilms. This suggests that inhibiting eDNA production can offer a potential management therapy of $A$. fumigatus infections [16]. There were however no particular changes in biofilm when tested against the combination of azoles and DNase; the reason might be that eDNA forms part of the ECM and is involved in biofilm stability rather than ergosterol biosynthesis which is targeted by azoles.

\subsection{Persister Cells}

The presence of persister cells is crucial in chronic fungal infection, they form a population of about $1 \%$ of dormant cells which are highly tolerant to antifungal agent and they ensure the survival of biofilm even after extensive and long-term course of antifungal therapy, thus promoting recurrence [19]. In an experiment comparing planktonic and biofilm states of C. albicans, it was observed that persister cells were present in the biofilm state only; this discovery helps in the explanation of the antifungal tolerance exhibited by fungal biofilms [20]. Although clinical resistance to amphotericin B is rather rarely reported [21], fungal biofilms are becoming more and more tolerant to this polyene; this is partly due to the presence of persister cells. Persister cells are believed to have a reduced membrane ergosterol levels compared to susceptible cells. With ergosterol on the cell mem- 
brane of fungal cells being the main target of amphotericin B, the latter is found to be substantially ineffective against persister cells thus creating an inhibitory reaction to the polyene [19]. There is a hypothesis that persister cells are present in C. albicans biofilm even after treatment, this is explained by a biphasic killing pattern post treatment, where a portion of fungal cells are left unaffected after a dose-response activity is observed [20]. Generation of miconazole-resistant persisters in C. albicans biofilms were induced by Superoxide dismutases (SODs). Through their inhibition by the Cu/Zn-Sod inhibitor, N,N-diethyldithiocarbamate (DDC) persister cells were found to be less [22]. Saccharomyces cerevisiae acts as a model for mycotic biofilm experiments and genetic observation showed persistence to be mediated by a down regulation of protein translation regulated by TORC1 and Ras pathway activities. The TORC1 pathway is in charge of cell cycle initiation and cell growth whereas the Ras signaling is responsible for programmed cell death after exposure to antifungal drugs [23]. A. fumigatus biofilms are also known to possess persister cells, and is believed to take part in the resistance to polyenes by acting as quiet variables of regular cells [1].

\subsection{Efflux Pumps}

Efflux pumps are transport proteins helping in the removal of toxic substrates from within the cells into the external environment, they help in maintaining homeostasis within the complex structure of biofilm. Increased efflux of the drug is mediated by ATP binding cassette (ABC) and the major facilitator superfamily (MFS) transporters. Genetic elements encoding efflux pumps contribute in antifungal resistance. A. fumigatus was predicted to have at least $49 \mathrm{ABC}$ family transporter and 278 MFS genes [24]. In previous reports, itraconazole resistance in A. fumigatus was due to overexpression of Atr1 clones, the gene being an $A B C$ transporter drug resistant gene [25]. Candida has at least 5 different drug resistance genes (CDR1 to CDR5) associated with drug efflux [26]. Azole resistance in C. albicans was often linked to presence of multidrug resistance (MDR) pumps, a member of the ATP transporters [27]. Analysis of biofilm resistance to voriconazole and efflux pump activity showed a consistent increase in efflux pump activity as biofilm matures from 8 hours to 24 hours [28]. Comparatively, in another study, the expression of CaMDR1 was detected mostly in early phases of growth of C. albicans biofilm [29] whereas in A. fumigatus biofilms, AfuMDR4 was upregulated in a 12 hour grown biofilm upon exposure to voriconazole, but down regulated when incubated for another 12 hours. It was therefore hypothesized that efflux pumps played a role in early stages of growth of $A$. fumigatus biofilms and regressed when ECM is produced in mature biofilms.

\subsection{Heat Shock Protein 90 (Hsp90)}

In bacteria, Hsp90 is found in abundance and acts as key regulators in multiple cellular signaling [30], in fungi on the other hand, they assist in the regulation of fungal signaling networks and has a part in drug resistance and biofilm formation [31].

Research on its implication with C.albicans demonstrated that it functions mainly by stabilizing phosphatase calcineurin and MaPk Mkc1 in planktonic cells. Inhibiting Hsp90 in planktonic C. albicans would cause a reduction in the levels of the above, however, none of these phenomena were observed in the biofilm state of $C$. albicans. This led to a theory that Hsp90 regulates drug resistance in biofilm through another kind of mechanism. Inhibiting Hsp90 in C. albicans biofilm allowed azoles to shift from ineffectual to highly efficacious both in vitro and in vivo. When geldanamycin, an Hsp90 inhibitor was combined with fluconazole, MIC values were observed to be reduced by more than 30 -fold. A reduction of almost $60 \%$ in matrix glucan level was observed with depletion of Hsp90, providing a link between Hsp90, glucan production and how they regulatedrug resistance in C.albicans biofilm. Experiments were performed on A. fumigatus biofilms with a combination of azoles (fluconazole, voriconazole) or echinocandins (caspofungin, micafungin) and Hsp90 inhibitor, geldanamycin. The results showed good synergy between voriconazole or echinocandins and geldanamycin, but not with fluconazole. Upon observation with confocal scanning microscopy, multiple broken and burst hyphae were scattered all over the biofilm when tested with caspofungin and geldanamycin; whereas hyphae were defined as flat and ribbonlike upon addition of both voriconazole and geldanamycin. These results confirmed the hypothesis that inhibition of Hsp90 induces changes in the morphologies of A. fumigatus biofilms in association with an improved antibiofilm effect of certain azoles or echinocandins on A. fumigatus biofilms [32]. Targeting Hsp90 may therefore provide a positive therapeutic strategy for biofilm infections caused by both C. albicans and A. fumigatus. 


\subsection{Ergosterol}

Ergosterol found on fungal cell wall is important for processes such as stabilization of proteins at the cell membrane as well as endocytosis and vacuole fusion [33]. It is the main target for the antifungals, polyenes and azoles. All polyenes have high affinity for this sterol to which they bind directly and induces the toxic effect by pore formation and ergosterol sequestration [34]. However, as biofilm starts to form and eventually matures, there was a clear evidence of increased resistance towards AMB. This was suggested to be due to a significant decrease in ergosterol content and to alterations in the cell wall [35]. Azoles on the other hand functions as inhibitor of ergosterol biosynthesis at the C-14 demethylation stage. Triazoles bind to lanosterol 14- $a$-demethylase (14- $a$-DM) encoded by ERG11 in Candida and CYP51A in Aspergillus; this leads to ergosterol depletion, with accumulation of lanosterol and other toxic 14- $a$ methylated sterols [36]. With the capability of yeast and mold to form biofilm with existence of an ECM, it was demonstrated that azoles were sequestered within the matrix, preventing them from reaching the cells. This therefore makes biofilms categorically resistant to azoles [37].

Eilidh Mowat et al. demonstrated in a study that amphotericin B was the most effective against mature $A$. fumigatus biofilms [38]. However, Lass-Florl et al. reported that minimum inhibitory concentration (MIC) of amphotericin B higher than $2 \mu \mathrm{g} / \mathrm{ml}$ were highly associated with a fatal outcome [39]. Voriconazole was effective mostly in early stages of the biofilm, but showed poorer ability to counteract fully grown intertwined hyphae. Caspofungin was, on the other hand, consistently ineffective against all stages of biofilms [38]. Because of the factors discussed above, new and improved therapeutic strategies have to be established. An approach could be to look into natural products such as traditional Chinese medicine and its combination with other antifungals.

\section{Traditional Chinese Medicine as an Alternative Antifungal Agent?}

Recently, research has shown great interest on natural products with potential antifungal properties. Traditional Chinese medicines (TCMs) or their extracts have gathered a lot of attention due to their easy availability and minimal side effects. More than 300 herbs have been known to have "pesticidal" activities, some even have antifungal potential and have been used in the clinical world for centuries [40]. Although studies on the effect of TCM on A. fumigatus are very scarce, there is a large quantity of research based on Candida spp. and how TCM inhibits their growth in vitro (Table 1). In an attempt to screen 56 widely used dried Chinese medical plants for their antifungal properties against A. fumigatus, C. albicans, Geotrichum candidum and Rhodoturula rubra, Blaszczyk and his team demonstrated that Flos Carthami (Carthamus tinctorius L.) was specifically effective against $A$. fumigatus with a growth inhibitory area of diameter $7 \mathrm{~cm}$ after 4 days. R. et rh. Rhei (Rheum palmatum L.) also proved effective against $A$. fumigatus as well as C. albicans [41]. Another study that included A. fumigatus as their test pathogens demonstrated that chrysophanol, an isolated compound of Rheum emodi rhizomes had significant antifungal actions on A. fumigatus with an MIC of $50 \mu \mathrm{g} / \mathrm{ml}$ [42].

With an increase in immunocompromised patients, it was shown that non-albicans candida such as Candida krusei or Candida glabrata contributed to more and more infections. C. Seneviratne et al. reported for the first time the antifungal effect of crude extracts of Rhizoma Coptidis and Cortex phellodendri Chinesis against $C$. krusei and C. glabrata with MIC values of $50 \mu \mathrm{g} / \mathrm{ml}$ and $100 \mu \mathrm{g} / \mathrm{ml}$ respectively. Berberine is the alkaloid found in Rhizoma Coptidis that contributed largely in its antifungal activities [43]. Their results concurred with previous works on the fact that berberine hydrochloride showed weak inhibition against $C$. albicans but demonstrated significant effect on C. krusei as well as C. glabrata. In another study where 40 TCMs were investigated against 8 superficial fungal strains, they demonstrated that Melaphis chinensis, Polygonum cuspidatum, Punica granatum and Schisandra chinensis were the 4 TCMs among the 8 tested to inhibit fungal growth with MIC value of $50 \mu \mathrm{g} / \mathrm{ml}$; the most susceptible fungi being trichophyton violaceum and tricophyton tonsurans [44]. They also hypothesized that variance in MICs compared to previous studies might be because of the usage of different parts of the plants thus inducing different pharmacological effects. For instance, Melia azedarach showed no changes in the growth of Trichophyton rubrum and Microsporum gypseum whereas in previous reports, the MIC value was significantly low (16 $\mu \mathrm{g} / \mathrm{ml})$ [45]. Punica granatum, however, which showed similar inhibitory results on all 8 fungi tested with MIC of $50 \mu \mathrm{g} / \mathrm{ml}$, also had good antifungal effects on dermatophytes, A. niger, C. albicans and even Cryptococcus ssp. in previous reports [46].

Berberine was found effective against Trichophyton mentagrophytes, Trichophyton rubrum, Microsporum canis and Microsporum gypseum with a 50\% inhibitory concentration ( $\left.\mathrm{IC}_{50}\right)$ of 2.1 to $26.6 \mu \mathrm{g} / \mathrm{ml}$. Berberine can be found in many herbs reputed to possess antifungal capabilities, and hence it might be a direct candidate for 
Table 1. MIC value of TCM on various fungi.

\begin{tabular}{|c|c|c|c|}
\hline Name of TCM & Fungi & MIC $(\mu \mathrm{g} / \mathrm{ml})$ & Reference \\
\hline $\begin{array}{c}\text { Rheum emodi } \\
\text { (anthraquinone derivatives) }\end{array}$ & $\begin{array}{c}\text { Candida albicans } \\
\text { Cryptococcus neoformans } \\
\text { Trichophyton mentagrophytes } \\
\text { Aspergillus fumigatus }\end{array}$ & $\begin{array}{c}50 \\
50 \\
25-50 \\
50\end{array}$ & Agarwal et al., 2000 \\
\hline Rhizoma coptidis & $\begin{array}{c}\text { Candida glabrata } \\
\text { Candida krusei }\end{array}$ & $\begin{array}{l}50 \\
50\end{array}$ & \\
\hline Cortex phellodendri chinesis & $\begin{array}{l}\text { Candida glabrata } \\
\text { Candida krusei }\end{array}$ & $\begin{array}{l}100 \\
100\end{array}$ & Seneviratne et al., 2008 \\
\hline $\begin{array}{l}\text { Melaphis chinensis, Polygonum } \\
\text { cuspidatum, Punica granatum, } \\
\text { Schisandra chinensis }\end{array}$ & $\begin{array}{l}\text { Tricophyton violaceum } \\
\text { Tricophyton tonsurans }\end{array}$ & $\begin{array}{l}50 \\
50\end{array}$ & Yang et al., 2015 \\
\hline $\begin{array}{c}\text { Jatrorrhizine } \\
\text { (Mahonia aquifolium) }\end{array}$ & $\begin{array}{l}\text { Tricophyton rubrum } \\
\text { Microsporum canis } \\
\text { Microsporum gyaseum } \\
\text { Candida albicans } \\
\text { Candida tropicalis }\end{array}$ & $\begin{array}{l}62.5 \\
62.5 \\
125 \\
500 \\
250\end{array}$ & Vollekova et al., 2003 \\
\hline Pseudolaric acid B & $\begin{array}{l}\text { Candida albicans } \\
\text { Candida krusei } \\
\text { Candida tropicalis } \\
\text { Candida dubliniensis } \\
\text { Candida glabrata } \\
\text { Candida guilliermondii }\end{array}$ & $\begin{array}{l}32 \\
64 \\
16 \\
64 \\
32 \\
32\end{array}$ & Yan et al. 2012 \\
\hline Ginsenosides & $\begin{array}{c}\text { Candida albicans } \\
\text { Saccharomyces cerevisiae }\end{array}$ & $\begin{array}{l}100 \\
50\end{array}$ & Sung et al. 2008 \\
\hline Baicelein & Candida albicans & 2 & Fu et al. 2011 \\
\hline Berberine & Candida albicans & 64 & Quan et al. 2006 \\
\hline
\end{tabular}

future therapeutic treatments. Berberine is also one of the main alkaloids of Mahonia aquifolium. However in a study undertaken by Volleková et al. they demonstrated that among the protoberberines of M. aquifolium (berberine, jatrorrhizine, palmative and columbamine), jatrorrhizine also had significant inhibitory actions especially against dermatophytes such as Trichophyton and Microsporum with MIC values of 62.5 to $125 \mu \mathrm{g} / \mathrm{ml}$ or 250 to $500 \mu \mathrm{g} / \mathrm{ml}$ for Candida spp. [47]. The antifungal effects of jatrorrhizine on dermatophytes were almost the same as that of fluconazole and biconazole. It has been previously reported that the mechanism of action of protoberberines, berberine and palmative, against $C$. albicans was believed to be caused by the inactivation of sterol 24-methyl transferase (24-SMT) and chitin synthase, both important enzymes in ergosterol and chitin biosynthesis [48]. Jatrorrhizine also showed similar antifungal properties, therefore, is believed to have similar mode of actions. However, according to the structural model of jatrorrhizine, it possesses an additional polar 2-methoxy3-hydroxy substitution compared to berberine and palmative. This free hydroxy group, together with inactivation of 24-SMT and chitin synthase, are reasons to consider jatrorrhizine as a potential target for future antifungal therapy.

Another promising alternative would be pseudolaric acid B, extracted from "tujingpi" or Cortex pseudolaricis; they have been known for their antifertility, cytotoxic, antigiogenic and antifungal activities. Pseudolaric acid B was observed to be effective against six different species of Candida namely, albicans, glabrata, krusei, tropicalis, dubliniensis and parapsilosis with MIC values ranging from 16 to $64 \mu \mathrm{g} / \mathrm{ml}$. These values were approximately similar to that of fluconazole. It has also been pointed out that pseudolaric acid B had clear, non-trailing endpoints, demonstrating the fungicidal instead of fungistatic characteristics of this plant extract, against Candida species [49]. Pseudolaric acid B could be a potential answer to the problematic drug resistance where nonalbicans candida have become infection-causing pathogens, especially when C. krusei is naturally resistant to fluconazole.

Ginseng as a well-known herb, is widely used in herbal medicines across East Asia. Ginseng stem-leaf saponins, which is often chosen over Ginseng roots due to its lower cost and abundance, contain active ingredients 
with similar pharmacological functions as their roots. Many saponins have antifungal properties and provide protection against potential pathogens [50]. The mechanism of saponin fungitoxicity is believed to originate from its ability to disrupt cellular membranes by binding with membrane sterols and causing loss of membrane integrity [51]. Ginseng stem-leaf saponins comprise of ginsenosides, polysacharides, triterpenoids, and flavonoids. Many of its medicinal effects are mostly attributed to ginsenosides; it also has multiple pharmacological actions affecting the central nervous system (CNS), cardiovascular system, growth-metabolism system and immune system, as well as anti-fatigue, anti-hyperglycemic, anti-obesity, anti-cancer, anti-oxidant and anti-aging activities. Ginseng stem-leaf saponins were shown to also have some antifungal effects on planktonic C. albicans [52]. In a study done by Woo Sang Sung et al. they demonstrated this effect with Korean red ginseng saponins. During in vitro drug susceptibility testing, the MIC value for ginsenosides ranged from 50 to $100 \mu \mathrm{g} / \mathrm{ml}$, showing antifungal activity against human pathogenic fungal strains. However, it showed less potent activity than amphotericin B which acted as a control with an MIC of $5 \mu \mathrm{g} / \mathrm{ml}$ on all fungal strains [53].

Although TCMs have been proven effective on Candida spp. and dermatophytes, very few is known about its action on A. fumigatus, let alone on biofilms. Further investigations are required for screening of TCMs against Aspergillus spp. and more importantly, the safety of these compounds must be established before clinical use.

\section{Combination Therapy. What Are the Options?}

As discussed above, there is a clear need to develop new strategies to overcome resistance of fungal biofilms. Discovery of new antifungal agents to be used in clinical settings has been lagging behind; although recently, efforts in drug combination have been made to overcome resistance to antifungal agents.

Since amphotericin B stays the preferred choice of antifungal therapy despite its high risk of nephrotoxicity, recent studies have been undertaken to lessen its drawbacks, in the meanwhile, reducing the effective dose of amphotericin B to avoid toxicity in renal tissues remains the main priority. Combining this polyene to another drug could accentuate its anti-biofilm activity. About $47 \%$ of transplant patients used a combinational antifungal therapy course in hope of expanding the antifungal spectrum [54]. In a study on the treatment of cryptococcal meningitis [55], the combination of fluconazole, amphotericin B and flucytosine resulted in better sterilization of the cerebrospinal fluid compared to treatment with fluconazole alone; greatest effect was observed after addition of amphotericin B (5.0 mg/kg/day), fluconazole ( $40 \mathrm{mg} / \mathrm{kg} /$ day) and flucytosine (100 mg/kg/day), with a $100 \%$ survival rate after 16 days of treatment. In this study, recurrences were reduced, however, high cost and worrisome side effects limit the use of combinations of common antifungal drugs. In another study, renal dysfunction was induced by amphotericin B, leading to rapid accumulation of flucytosine and raising the patient's risk of hematological toxicity [56]. Hence, it is important to master the mechanism of each class of antifungal agents to avoid negative interactions or complications.

Controversies over the interaction of azoles-polyenes have been discussed in a few articles. Azoles function as inhibitors of ergosterol synthesis, however, polyenes need ergosterol to function. Azoles damaging part of fungus is essential for the activity of polyenes, making these two antifungal agents antagonistic. Another proposed mechanism for this interaction was that amphotericin B interferes with the cell membrane-associated protease, enabling the passage of itraconazole into the cell [57]. It is however difficult to replicate the amphotericin $\mathrm{B}$-azole interaction in vitro because the two drugs possess different time course actions; amphotericin B has rapid fungicidal activity and tends to obscure the effect of slower azoles [58] whereas amphotericin B shows good synergy with echinocandin, caspofungin [59]. In an experiment undertaken by Weixia Liu and his team, they showed that the combination of caspofungin and amphotericin B had a synergistic inhibitory activity against 8 out of 11 A. fumigatus biofilms, with fractional inhibitory concentration index (FICI) of below 0.5 [60].

The focus of new research has been based on the combination of antifungals with non-antifungals. This research focus has helped reduce the high costs and serious side effects that come along with combination of antifungal drugs. Baicalein, a popular Chinese herb showed synergistic actions on C. albicans when combined with amphotericin B; the polyene's $\mathrm{MIC}_{50}$ was reduced from $0.375 \mu \mathrm{g} / \mathrm{ml}$ to $0.25 \mu \mathrm{g} / \mathrm{ml}$ whereas the $\mathrm{MIC}_{50}$ of baicalein was lowered from $2 \mu \mathrm{g} / \mathrm{ml}$ to $0.0117 \mu \mathrm{g} / \mathrm{ml}$ [61]. Pseudolaric acid B (PSB) with fluconazole also demonstrated significant synergism when tested against fluconazole-resistant C. albicans; with an MIC value reduced by almost 5-fold [49] [62]. The above two TCMs have been identified as having a reduction in drug efflux, alteration in sterol biosynthesis and anti biofilm actions as their means of counteracting fungal infections [63]. Ber- 
berine, as mentioned above showed weak activity against $C$. albicans. In a study where berberine chloride (BBR) was combined with fluconazole to test against fluconazole resistant isolates of $C$. albicans, they noticed a significant reduction in MIC of either of the individual agent with $\mathrm{MIC}_{80}$ of fluconazole dropping from $\geq 64 \mu \mathrm{g} / \mathrm{ml}$ to $\leq 0.125$ - $2 \mu \mathrm{g} / \mathrm{ml}$ whereas the MIC of BBR was reduced by at least 6 fold. $100 \%$ of the isolates showed synergism in terms of $\mathrm{MIC}_{80}$ with median FICI of 0.034 [64]. They concluded that the combination of these two drugs could be a good option to treat fluconazole resistant $C$. albicans in vitro. However, while the mechanism behind this interaction is still not completely understood, they hypothesized that it may be due to the inhibition of sterol 24-methyl transferase by BBR, together with active efflux of the azole with overexpression of CDR, MDR1, or FLU1 and also alterations of target enzymes.

Due to poor permeability across the fungal membrane, amphotericin B must be administered at a high dosage making the rise in side effects problematic; combining it to berberine was considered relatively safe considering that its fatal dose had to exceed $23 \mathrm{mg} / \mathrm{kg}$ of body weight in mice [65]. The study of Han et al. was the first to investigate the combination effect of berberine and amphotericin B on C. albicans infected mice. He used the enumeration of colony forming units (CFU) to determine growth inhibition and demonstrated that berberine alone was able to inhibit growth of $C$. albicans by approximately $60 \%$ compares to its control culture. Combining $50 \mu \mathrm{g} / \mathrm{ml}$ berberine with $0.5 \mu \mathrm{g} / \mathrm{ml}$ amphotericin B reduced CFU from $1.211 \times 10^{8} \mathrm{CFU} / \mathrm{ml}$ to $1.1 \times 10^{4}$ $\mathrm{CFU} / \mathrm{ml}$; doubling the concentration of amphotericin B resulted to $>90 \%$ CFU reduction. In vivo synergistic effect was observed when infected mice were given a mixture of the 2 drugs with a survival rate of 23 days longer. This rate of survival was similar to mice given 4 times the average amphotericin B dosage.

\section{Conclusion}

Medical scientists came to the conclusion that fungal infections caused by the formation of biofilms are one of the many diseases whose pathogenesis and progression are becoming more complicated. A single drug may not be effective enough or may be hampered by severe side effects or resistance to the drug. There is therefore a serious need of new treatment protocol, with minimum side effects, to combat these life threatening diseases and reduce recurrences. Combination of antifungal agents with TCM has proven to be relatively effective against planktonic dermatophytes and Candida species but the reports on A. fumigatus and fungal biofilms are rare. Further investigations need to be done to understand the mechanism of action of TCMs and how they can inhibit the growth of A. fumigatus as well as its biofilms.

\section{Conflict of Interest}

None.

\section{References}

[1] Kaur, S. and Singh, S. (2014) Biofilm Formation by Aspergillus fumigatus. Medical Mycology, 52, 2-9.

[2] Nett, J.E., Crawford, K., Marchillo, K. and Andes, D.R. (2010) Role of Fks1p and Matrix Glucan in Candida Albicans Biofilm Resistance to an Echinocandin, Pyrimidine, and Polyene. Antimicrobial Agents and Chemotherapy, 54, 35053508. http://dx.doi.org/10.1128/AAC.00227-10

[3] Denning, D.W. (1998) Invasive Aspergillosis. Clinical Infectious Diseases, 26, 781-803; quiz 804-805. http://dx.doi.org/10.1086/513943

[4] Srinivasan, A., Lopez-Ribot, J.L. and Ramasubramanian, A.K. (2014) Overcoming Antifungal Resistance. Drug Discovery Today: Technologies, 11, 65-71. http://dx.doi.org/10.1016/j.ddtec.2014.02.005

[5] Karthaus, M. (2010) Guideline Based Treatment of Invasive Aspergillosis. Mycoses, 53, 36-43. http://dx.doi.org/10.1111/j.1439-0507.2009.01840.x

[6] Pierce, C.G., Srinivasan, A., Uppuluri, P., Ramasubramanian, A.K. and Lopez-Ribot, J.L. (2013) Antifungal Therapy with an Emphasis on Biofilms. Current Opinion in Pharmacology, 13, 726-730. http://dx.doi.org/10.1016/j.coph.2013.08.008

[7] Ramage, G., Rajendran, R., Gutierrez-Correa, M., Jones, B. and Williams, C. (2011) Aspergillus Biofilms: Clinical and Industrial Significance. FEMS Microbiology Letters, 324, 89-97. http://dx.doi.org/10.1111/j.1574-6968.2011.02381.x

[8] Ramage, G., Saville, S.P., Thomas, D.P. and Lopez-Ribot, J.L. (2005) Candida Biofilms: An Update. Eukaryotic Cell, 4, 633-638. http://dx.doi.org/10.1128/EC.4.4.633-638.2005 
[9] Mowat, E., Williams, C., Jones, B., McChlery, S. and Ramage, G. (2009) The Characteristics of Aspergillus fumigatus Mycetoma Development: Is This a Biofilm? Medical Mycology, 47, S120-S126. http://dx.doi.org/10.1080/13693780802238834

[10] Ramage, G., Mowat, E., Jones, B., Williams, C. and Lopez-Ribot, J. (2009) Our Current Understanding of Fungal Biofilms. Critical Reviews in Microbiology, 35, 340-355. http://dx.doi.org/10.3109/10408410903241436

[11] Beauvais, A., Schmidt, C., Guadagnini, S., Roux, P., Perret, E., Henry, C., Paris, S., Mallet, A., Prevost, M.C. and Latge, J.P. (2007) An Extracellular Matrix Glues Together the Aerial-Grown Hyphae of Aspergillus fumigatus. Cellular Microbiology, 9, 1588-1600. http://dx.doi.org/10.1111/j.1462-5822.2007.00895.X

[12] Reichhardt, C., Ferreira, J.A., Joubert, L.M., Clemons, K.V., Stevens, D.A. and Cegelski, L. (2015) Analysis of the Aspergillus fumigatus Biofilm Extracellular Matrix by Solid-State Nuclear Magnetic Resonance Spectroscopy. Eukaryotic Cell, 14, 1064-1072. http://dx.doi.org/10.1128/EC.00050-15

[13] Miller, R.A. and Britigan, B.E. (1997) Role of Oxidants in Microbial Pathophysiology. Clinical Microbiology Reviews, 10, 1-18.

[14] Banerjee, B., Greenberger, P.A., Fink, J.N. and Kurup, V.P. (1998) Immunological Characterization of Asp f 2, a Major Allergen from Aspergillus fumigatus Associated with Allergic Bronchopulmonary Aspergillosis. Infection and Immunity, 66, 5175-5182.

[15] Jahn, B., Langfelder, K., Schneider, U., Schindel, C. and Brakhage, A.A. (2002) PKSP-Dependent Reduction of Phagolysosome Fusion and Intracellular Kill of Aspergillus fumigatus Conidia by Human Monocyte-Derived Macrophages. Cellular Microbiology, 4, 793-803. http://dx.doi.org/10.1046/j.1462-5822.2002.00228.x

[16] Rajendran, R., Williams, C., Lappin, D.F., Millington, O., Martins, M. and Ramage, G. (2013) Extracellular DNA Release Acts as an Antifungal Resistance Mechanism in Mature Aspergillus fumigatus Biofilms. Eukaryotic Cell, 12, 420-429. http://dx.doi.org/10.1128/EC.00287-12

[17] Whitchurch, C.B., Tolker-Nielsen, T., Ragas, P.C. and Mattick, J.S. (2002) Extracellular DNA Required for Bacterial Biofilm Formation. Science, 295, 1487. http://dx.doi.org/10.1126/science.295.5559.1487

[18] Martins, M., Uppuluri, P., Thomas, D.P., Cleary, I.A., Henriques, M., Lopez-Ribot, J.L. and Oliveira, R. (2010) Presence of Extracellular DNA in the Candida albicans Biofilm Matrix and Its Contribution to Biofilms. Mycopathologia, 169, 323-331. http://dx.doi.org/10.1007/s11046-009-9264-y

[19] Bojsen, R., Regenberg, B., Gresham, D. and Folkesson, A. (2016) A Common Mechanism Involving the TORC1 Pathway Can Lead to Amphotericin B-Persistence in Biofilm and Planktonic Saccharomyces cerevisiae Populations. Scientific Reports, 6, No. 21874. http://dx.doi.org/10.1038/srep21874

[20] LaFleur, M.D., Kumamoto, C.A. and Lewis, K. (2006) Candida albicans Biofilms Produce Antifungal-Tolerant Persister Cells. Antimicrobial Agents and Chemotherapy, 50, 3839-3846. http://dx.doi.org/10.1128/AAC.00684-06

[21] Mesa-Arango, A.C., Scorzoni, L. and Zaragoza, O. (2012) It Only Takes One to Do Many Jobs: Amphotericin B as Antifungal and Immunomodulatory Drug. Frontiers in Microbiology, 3, Article 286. http://dx.doi.org/10.3389/fmicb.2012.00286

[22] Bink, A., Vandenbosch, D., Coenye, T., Nelis, H., Cammue, B.P. and Thevissen, K. (2011) Superoxide Dismutases Are Involved in Candida albicans Biofilm Persistence against Miconazole. Antimicrobial Agents and Chemotherapy, 55, 4033-4037. http://dx.doi.org/10.1128/AAC.00280-11

[23] Martin, D.E., Soulard, A. and Hall, M.N. (2004) TOR Regulates Ribosomal Protein Gene Expression via PKA and the Forkhead Transcription Factor FHL1. Cell, 119, 969-979. http://dx.doi.org/10.1016/j.cell.2004.11.047

[24] Nierman, W.C., Pain, A., Anderson, M.J., Wortman, J.R., Kim, H.S., Arroyo, J., Berriman, M., Abe, K., Archer, D.B., Bermejo, C., Bennett, J., Bowyer, P., Chen, D., Collins, M., Coulsen, R., Davies, R., Dyer, P.S., Farman, M., Fedorova, N., Fedorova, N., Feldblyum, T.V., Fischer, R., Fosker, N., Fraser, A., Garcia, J.L., Garcia, M.J., Goble, A., Goldman, G.H., Gomi, K., Griffith-Jones, S., Gwilliam, R., Haas, B., Haas, H., Harris, D., Horiuchi, H., Huang, J., Humphray, S., Jimenez, J., Keller, N., Khouri, H., Kitamoto, K., Kobayashi, T., Konzack, S., Kulkarni, R., Kumagai, T., Lafon, A., Latge, J.P., Li, W., Lord, A., Lu, C., Majoros, W.H., May, G.S., Miller, B.L., Mohamoud, Y., Molina, M., Monod, M., Mouyna, I., Mulligan, S., Murphy, L., O’Neil, S., Paulsen, I., Penalva, M.A., Pertea, M., Price, C., Pritchard, B.L., Quail, M.A., Rabbinowitsch, E., Rawlins, N., Rajandream, M.A., Reichard, U., Renauld, H., Robson, G.D., Rodriguez de Cordoba, S., Rodriguez-Pena, J.M., Ronning, C.M., Rutter, S., Salzberg, S.L., Sanchez, M., Sanchez-Ferrero, J.C., Saunders, D., Seeger, K., Squares, R., Squares, S., Takeuchi, M., Tekaia, F., Turner, G., Vazquez de Aldana, C.R., Weidman, J., White, O., Woodward, J., Yu, J.H., Fraser, C., Galagan, J.E., Asai, K., Machida, M., Hall, N., Barrell, B. and Denning, D.W. (2005) Genomic Sequence of the Pathogenic and Allergenic Filamentous Fungus Aspergillus fumigatus. Nature, 438, 1151-1156. http://dx.doi.org/10.1038/nature04332

[25] Slaven, J.W., Anderson, M.J., Sanglard, D., Dixon, G.K., Bille, J., Roberts, I.S. and Denning, D.W. (2002) Increased Expression of a Novel Aspergillus fumigatus ABC Transporter Gene, atrF, in the Presence of Itraconazole in an Itraconazole Resistant Clinical Isolate. Fungal Genetics and Biology, 36, 199-206. 
http://dx.doi.org/10.1016/S1087-1845(02)00016-6

[26] Sanglard, D., Ischer, F., Calabrese, D., Micheli, M. and Bille, J. (1998) Multiple Resistance Mechanisms to Azole Antifungals in Yeast Clinical Isolates. Drug Resistance Updates, 1, 255-265. http://dx.doi.org/10.1016/S1368-7646(98)80006-X

[27] Wakiec, R., Prasad, R., Morschhauser, J., Barchiesi, F., Borowski, E. and Milewski, S. (2007) Voriconazole and Multidrug Resistance in Candida albicans. Mycoses, 50, 109-115. http://dx.doi.org/10.1111/j.1439-0507.2006.01327.x

[28] Rajendran, R., Mowat, E., McCulloch, E., Lappin, D.F., Jones, B., Lang, S., Majithiya, J.B., Warn, P., Williams, C. and Ramage, G. (2011) Azole Resistance of Aspergillus fumigatus Biofilms Is Partly Associated with Efflux Pump Activity. Antimicrobial Agents and Chemotherapy, 55, 2092-2097. http://dx.doi.org/10.1128/AAC.01189-10

[29] Mukherjee, P.K., Chandra, J., Kuhn, D.M. and Ghannoum, M.A. (2003) Mechanism of Fluconazole Resistance in Candida albicans Biofilms: Phase-Specific Role of Efflux Pumps and Membrane Sterols. Infection and Immunity, 71, 4333-4340. http://dx.doi.org/10.1128/IAI.71.8.4333-4340.2003

[30] Wandinger, S.K., Richter, K. and Buchner, J. (2008) The Hsp90 Chaperone Machinery. The Journal of Biological Chemistry, 283, 18473-18477. http://dx.doi.org/10.1074/jbc.R800007200

[31] Becherelli, M., Tao, J. and Ryder, N.S. (2013) Involvement of Heat Shock Proteins in Candida albicans Biofilm Formation. Journal of Molecular Microbiology and Biotechnology, 23, 396-400.

[32] Robbins, N., Uppuluri, P., Nett, J., Rajendran, R., Ramage, G., Lopez-Ribot, J.L., Andes, D. and Cowen, L.E. (2011) Hsp90 Governs Dispersion and Drug Resistance of Fungal Biofilms. PLoS Pathogens, 7, e1002257. http://dx.doi.org/10.1371/journal.ppat.1002257

[33] Zhang, Y.Q., Gamarra, S., Garcia-Effron, G., Park, S., Perlin, D.S. and Rao, R. (2010) Requirement for Ergosterol in V-ATPase Function Underlies Antifungal Activity of Azole Drugs. PLoS Pathogens, 6, e1000939. http://dx.doi.org/10.1371/journal.ppat.1000939

[34] Palacios, D.S., Dailey, I., Siebert, D.M., Wilcock, B.C. and Burke, M.D. (2011) Synthesis-Enabled Functional Group Deletions Reveal Key Underpinnings of Amphotericin B Ion Channel and Antifungal Activities. Proceedings of the National Academy of Sciences of the United States of America, 108, 6733-6738. http://dx.doi.org/10.1073/pnas.1015023108

[35] Khot, P.D., Suci, P.A., Miller, R.L., Nelson, R.D. and Tyler, B.J. (2006) A Small Subpopulation of Blastospores in Candida albicans Biofilms Exhibit Resistance to Amphotericin B Associated with Differential Regulation of Ergosterol and Beta-1,6-Glucan Pathway Genes. Antimicrobial Agents and Chemotherapy, 50, 3708-3716. http://dx.doi.org/10.1128/AAC.00997-06

[36] Chamilos, G. and Kontoyiannis, D.P. (2005) Update on Antifungal Drug Resistance Mechanisms of Aspergillus fumigatus. Drug Resistance Updates, 8, 344-358. http://dx.doi.org/10.1016/j.drup.2006.01.001

[37] Perlin, D.S., Shor, E. and Zhao, Y. (2015) Update on Antifungal Drug Resistance. Current Clinical Microbiology Reports, 2, 84-95. http://dx.doi.org/10.1007/s40588-015-0015-1

[38] Mowat, E., Lang, S., Williams, C., McCulloch, E., Jones, B. and Ramage, G. (2008) Phase-Dependent Antifungal Activity against Aspergillus fumigatus Developing Multicellular Filamentous Biofilms. Journal of Antimicrobial Chemotherapy, 62, 1281-1284. http://dx.doi.org/10.1093/jac/dkn402

[39] Lass-Florl, C., Kofler, G., Kropshofer, G., Hermans, J., Kreczy, A., Dierich, M.P. and Niederwieser, D. (1998) In-Vitro Testing of Susceptibility to Amphotericin B Is a Reliable Predictor of Clinical Outcome in Invasive Aspergillosis. Journal of Antimicrobial Chemotherapy, 42, 497-502. http://dx.doi.org/10.1093/jac/42.4.497

[40] Liu, X., Han, Y., Peng, K., Liu, Y., Li, J. and Liu, H. (2011) Effect of Traditional Chinese Medicinal Herbs on Candida spp. from Patients with HIV/AIDS. Advances in Dental Research, 23, 56-60. http://dx.doi.org/10.1177/0022034511399286

[41] Blaszczyk, T., Krzyzanowska, J. and Lamer-Zarawska, E. (2000) Screening for Antimycotic Properties of 56 Traditional Chinese Drugs. Phytotherapy Research, 14, 210-212. http://dx.doi.org/10.1002/(SICI)1099-1573(200005)14:3<210::AID-PTR591>3.0.CO;2-7

[42] Agarwal, S.K., Singh, S.S., Verma, S. and Kumar, S. (2000) Antifungal Activity of Anthraquinone Derivatives from Rheum emodi. Journal of Ethnopharmacology, 72, 43-46. http://dx.doi.org/10.1016/S0378-8741(00)00195-1

[43] Seneviratne, C.J., Wong, R.W. and Samaranayake, L.P. (2008) Potent Anti-Microbial Activity of Traditional Chinese Medicine Herbs against Candida Species. Mycoses, 51, 30-34.

[44] Yang, F., Ding, S., Liu, W., Liu, J., Zhang, W., Zhao, Q. and Ma, X. (2015) Antifungal Activity of 40 TCMs Used Individually and in Combination for Treatment of Superficial Fungal Infections. Journal of Ethnopharmacology, 163, 88-93. http://dx.doi.org/10.1016/j.jep.2015.01.025

[45] Orhan, I.E., Guner, E., Ozcelik, B., Senol, F.S., Caglar, S.S., Emecen, G., Kocak, O. and Sener, B. (2012) Assessment of Antimicrobial, Insecticidal and Genotoxic Effects of Melia azedarach L. (Chinaberry) Naturalized in Anatolia. International Journal of Food Sciences and Nutrition, 63, 560-565. http://dx.doi.org/10.3109/096374866.2011.642855 
[46] Ponnusamy, K., Petchiammal, C., Mohankumar, R. and Hopper, W. (2010) In Vitro Antifungal Activity of Indirubin Isolated from a South Indian Ethnomedicinal Plant Wrightia tinctoria R. Br. Journal of Ethnopharmacology, 132, 349-354. http://dx.doi.org/10.1016/j.jep.2010.07.050

[47] Vollekova, A., Kost’alova, D., Kettmann, V. and Toth, J. (2003) Antifungal Activity of Mahonia aquifolium Extract and Its Major Protoberberine Alkaloids. Phytotherapy Research, 17, 834-837. http://dx.doi.org/10.1002/ptr.1256

[48] Park, K.S., Kang, K.C., Kim, J.H., Adams, D.J., Johng, T.N. and Paik, Y.K. (1999) Differential Inhibitory Effects of Protoberberines on Sterol and Chitin Biosyntheses in Candida albicans. ChemotherJournal of Antimicrobial Chemotherapy, 43, 667-674. http://dx.doi.org/10.1093/jac/43.5.667

[49] Yan, Z., Hua, H., Xu, Y. and Samaranayake, L.P. (2012) Potent Antifungal Activity of Pure Compounds from Traditional Chinese Medicine Extracts against Six Oral Candida Species and the Synergy with Fluconazole against AzoleResistant Candida albicans. Evidence-Based Complementary and Alternative Medicine, 2012, Article ID: 106583.

[50] Papadopoulou, K., Melton, R.E., Leggett, M., Daniels, M.J. and Osbourn, A.E. (1999) Compromised Disease Resistance in Saponin-Deficient Plants. Proceedings of the National Academy of Sciences of the United States of America, 96, 12923-12928. http://dx.doi.org/10.1073/pnas.96.22.12923

[51] Zhao, X., Gao, J., Song, C., Fang, Q., Wang, N., Zhao, T., Liu, D. and Zhou, Y. (2012) Fungal Sensitivity to and Enzymatic Deglycosylation of Ginsenosides. Phytochemistry, 78, 65-71. http://dx.doi.org/10.1016/j.phytochem.2012.02.027

[52] Jiang, M., Huang, X., Shen, L., Zhou, F., Tu, W. and Shi, W. (2011) Antifungal Sensitivity of Two Chinese Traditional Drugs against Candida in Vitro. Chinese Journal of Mycology, 6, 26-30.

[53] Sung, W.S. and Lee, D.G. (2008) In Vitro Candidacidal Action of Korean Red Ginseng Saponins against Candida albicans. Biological and Pharmaceutical Bulletin, 31, 139-142. http://dx.doi.org/10.1248/bpb.31.139

[54] Hatipoglu, N. and Hatipoglu, H. (2013) Combination Antifungal Therapy for Invasive Fungal Infections in Children and Adults. Expert Review of Anti-Infective Therapy, 11, 523-535. http://dx.doi.org/10.1586/eri.13.29

[55] Larsen, R.A., Bauer, M., Thomas, A.M. and Graybill, J.R. (2004) Amphotericin B and Fluconazole, a Potent Combination Therapy for Cryptococcal Meningitis. Antimicrobial Agents and Chemotherapy, 48, 985-991. http://dx.doi.org/10.1128/AAC.48.3.985-991.2004

[56] Groll, A.H., Gea-Banacloche, J.C., Glasmacher, A., Just-Nuebling, G., Maschmeyer, G. and Walsh, T.J. (2003) Clinical Pharmacology of Antifungal Compounds. Infectious Disease Clinics of North America, 17, 159-191. http://dx.doi.org/10.1016/S0891-5520(02)00068-5

[57] Moore, C.B., Sayers, N., Mosquera, J., Slaven, J. and Denning, D.W. (2000) Antifungal Drug Resistance in Aspergillus. Journal of Infection, 41, 203-220. http://dx.doi.org/10.1053/jinf.2000.0747

[58] Steinbach, W.J., Stevens, D.A. and Denning, D.W. (2003) Combination and Sequential Antifungal Therapy for Invasive Aspergillosis: Review of Published in Vitro and in Vivo Interactions and 6281 Clinical Cases from 1966 to 2001. Clinical Infectious Diseases, 37, S188-S224. http://dx.doi.org/10.1086/376524

[59] Arikan, S., Lozano-Chiu, M., Paetznick, V. and Rex, J.H. (2002) In Vitro Synergy of Caspofungin and Amphotericin B against Aspergillus and Fusarium spp. Antimicrobial Agents and Chemotherapy, 46, 245-247. http://dx.doi.org/10.1128/AAC.46.1.245-247.2002

[60] Liu, W., Li, L., Sun, Y., Chen, W., Wan, Z., Li, R. and Liu, W. (2012) Interaction of the Echinocandin Caspofungin with Amphotericin B or Voriconazole against Aspergillus Biofilms in Vitro. Antimicrobial Agents and Chemotherapy, 56, 6414-6416. http://dx.doi.org/10.1128/AAC.00687-12

[61] Fu, Z., Lu, H., Zhu, Z., Yan, L., Jiang, Y. and Cao, Y. (2011) Combination of Baicalein and Amphotericin B Accelerates Candida albicans Apoptosis. Biological and Pharmaceutical Bulletin, 34, 214-218. http://dx.doi.org/10.1248/bpb.34.214

[62] Guo, N., Ling, G., Liang, X., Jin, J., Fan, J., Qiu, J., Song, Y., Huang, N., Wu, X., Wang, X., Deng, X., Deng, X. and Yu, L. (2011) In Vitro Synergy of Pseudolaric Acid B and Fluconazole against Clinical Isolates of Candida albicans. Mycoses, 54, e400-e406. http://dx.doi.org/10.1111/j.1439-0507.2010.01935.X

[63] Liu, S., Hou, Y., Chen, X., Gao, Y., Li, H. and Sun, S. (2014) Combination of Fluconazole with Non-Antifungal Agents: A Promising Approach to Cope with Resistant Candida albicans Infections and Insight into New Antifungal Agent Discovery. International Journal of Antimicrobial Agents, 43, 395-402. http://dx.doi.org/10.1016/j.ijantimicag.2013.12.009

[64] Quan, H., Cao, Y.Y., Xu, Z., Zhao, J.X., Gao, P.H., Qin, X.F. and Jiang, Y.Y. (2006) Potent in Vitro Synergism of Fluconazole and Berberine Chloride against Clinical Isolates of Candida albicans Resistant to Fluconazole. Antimicrobial Agents and Chemotherapy, 50, 1096-1099. http://dx.doi.org/10.1128/AAC.50.3.1096-1099.2006

[65] Han, Y. and Lee, J.H. (2005) Berberine Synergy with Amphotericin B against Disseminated Candidiasis in Mice. Biological and Pharmaceutical Bulletin, 28, 541-544. http://dx.doi.org/10.1248/bpb.28.541 